\title{
Alcohol Use, Human Capital, and Wages
}

By: Jeremy W. Bray

Bray, J. W. (2005). Alcohol use, human capital, and wages. Journal of Labor Economics, 23(2), 279-312.

Made available courtesy of University of Chicago

Press: http://www.jstor.org/stable/10.1086/428025

\section{(C) 2005 by University of Chicago Press}

\begin{abstract}
:
This article develops and estimates a model of wage determination that isolates the effects of alcohol use on wages as mediated through human capital accumulation. Although generally insignificant, estimation results suggest that moderate alcohol use while in school or working has a positive effect on the returns to education or experience, and therefore on human capital accumulation, but heavier drinking reduces this gain slightly. Based on these results, alcohol use does not appear to adversely affect returns to education or work experience and therefore has no negative effect on the efficiency of education or experience in forming human capital.
\end{abstract}

Keywords: alcohol use | wages | education | human capital | work experience

\section{Article:}

***Note: Full text of article below 


\title{
Alcohol Use, Human Capital, and Wages
}

\author{
Jeremy W. Bray, RTI International
}

This article develops and estimates a model of wage determination that isolates the effects of alcohol use on wages as mediated through human capital accumulation. Although generally insignificant, estimation results suggest that moderate alcohol use while in school or working has a positive effect on the returns to education or experience, and therefore on human capital accumulation, but heavier drinking reduces this gain slightly. Based on these results, alcohol use does not appear to adversely affect returns to education or work experience and therefore has no negative effect on the efficiency of education or experience in forming human capital.

\section{Introduction}

Alcohol is the most widely consumed drug among American youth. In $2000,27.5 \%$ of youth ages $12-20$ reported drinking alcohol in the past month, and $18.7 \%$ reported binge drinking in the past month (SAMHSA 2002). Alcohol abuse, both by adults and by youth, has been linked to a number of negative social consequences, including crime, traffic accidents, and increased health care expenditures. Over the past decade, one

I would like to thank Thomas Mroz, Gary Zarkin, Alexander Cowell, and Donald Kenkel for their comments. Keith Davis and Berna Demiralp provided research and programming support, and Susan Murchie and Judy Cannada provided editorial and word processing support. RTI International is a trade name of Research Triangle Research. Partial funding for this work was provided by the National Institute on Alcohol Abuse and Alcoholism (NIAAA) Grant no. 1 R01-AA12788 and by a Professional Development Award from RTI. The views expressed in this article are not necessarily those of NIAAA or of RTI. All remaining errors are mine. Contact the author at bray@rti.org.

[Journal of Labor Economics, 2005, vol. 23, no. 2]

(C) 2005 by The University of Chicago. All rights reserved.

0734-306X/2005/2302-0004\$10.00 
such consequence that has been widely studied by economists is the potential impact of alcohol use and abuse on labor market productivity as measured by wages and earnings.

Results of this work are largely mixed. In their chapter on alcohol in the Handbook of Health Economics, Cook and Moore (2000) summarize the literature on the effects of alcohol use on productivity. It appears that light to moderate alcohol users of both sexes have higher earnings, but alcohol-dependent men earn less. Furthermore, alcohol use has little to no effect on labor supply. The one consistent finding is that alcohol users complete significantly fewer years of education than nonusers. The negative relationship between schooling and alcohol use led Cook and Moore to conclude that "much of the effect of drinking on productivity may be indirect, mediated by the accumulation of human capital" (1658).

The literature on which Cook and Moore (2000) base this conclusion has two main limitations, however. First, the previous literature has not developed a coherent theoretical model linking alcohol use to wages through a human capital mechanism. The previous literature has typically estimated standard wage or earnings equations that also include a measure of alcohol use or alcohol dependence. Although these specifications provide useful correlations between alcohol use and wages, they do not isolate the causal mechanism through which alcohol use affects wages, and therefore they cannot distinguish the human capital effects of alcohol use from other possible effects, such as health effects.

The second main limitation of the previous literature has been its failure to adequately address two key empirical issues when estimating wage equations: endogeneity and sample selection (Cook and Moore 2000). Any equation that contains a choice variable (e.g., alcohol use) is likely to suffer from endogeneity bias. Furthermore, because wages are both a component of income and the price of an individual's time, economic theory suggests that alcohol use is endogenous in a wage equation. Another potentially endogenous variable is educational attainment. An extensive literature attempts to deal with the potential endogeneity of education in wage equations and, given the clear link between alcohol use and educational attainment, it would seem especially important to address the potential endogeneity of education when estimating the relationship between alcohol use and wages. The alcohol-wage literature has typically relied on instrumental variables (IV) techniques to correct for the endogeneity of alcohol use, but these estimates have generally been very imprecise. The alcohol-wage literature has largely ignored the potential endogeneity of educational attainment.

The other key empirical issue, sample selection, arises because not all individuals work and not all individuals consume alcohol. Thus, both wages and alcohol demand are bounded by zero, with many individuals actually observed at zero. Given the difficulty of simultaneously address- 
ing both endogeneity and sample selection, most of the previous literature has ignored the sample selection issue. Those studies that have addressed sample selection have typically not corrected for endogeneity. Few if any studies have addressed both issues simultaneously.

This article derives a theoretical and empirical model of wage determination that isolates the effect of alcohol use on wages as mediated through the formation and accumulation of human capital. The intuition behind the model is straightforward: holding constant the total years of education, estimate a separate wage return for years of education and experience acquired in periods in which an individual drank versus periods in which he did not and compare the rates of return. If the rates of return are equal, then alcohol use has no effect on human capital formation. If the rates of return are not equal, then alcohol use does have an effect on human capital formation.

The theoretical model provides a concise economic interpretation of the estimated parameters that clearly links them to theoretical parameters of the underlying human capital production function. To address both endogeneity and sample selection simultaneously, the discrete factor method (DFM) is used to estimate the model (Heckman and Singer 1984; Mroz 1999). Because this method allows alcohol use, educational attainment, and work experience to be treated as endogenous variables, it controls for the possibility that alcohol use affects both the quality and quantity of schooling and work experience.

\section{Background}

Most economic studies that consider a link between alcohol use and productivity do so by examining the relationship between alcohol use and wages (e.g., Berger and Leigh 1988; Bryant, Sumaranayake, and Wilhite 1992; Mullahy and Sindelar 1993; Kenkel and Ribar 1994; French and Zarkin 1995; Heien 1996; Zarkin et al. 1998). In general, these studies have found a positive relationship between simple alcohol use and wages but a negative relationship between alcohol abuse and wages (Cook and Moore 2000).

One of the first studies to examine a possible link between alcohol use and wages was Mullahy and Sindelar (1989). The goal of that study was to examine in more detail the structural relationships among family background, alcoholism, education, earnings, and occupation. Specifically, Mullahy and Sindelar used a life-cycle framework to link alcoholism to outcomes later in life. They found that early onset alcoholism reduced years of education completed, which, in turn, had negative effects on earnings and occupational status.

Although Mullahy and Sindelar used a life-cycle framework, they did not derive a formal life-cycle model linking alcoholism and labor market 
outcomes. Rather, they relied on a review of empirical studies on earnings, occupational choice, health, and educational attainment to motivate their own empirical model. Because of this, their empirical model is essentially a standard wage or earnings equation with an indicator for alcoholism included as an explanatory variable. Although Mullahy and Sindelar's empirical specification is broadly consistent with a life-cycle model of labor market outcomes, they do not attempt to isolate theoretically a human capital effect.

Economists have also examined the link between alcohol use and schooling outcomes, such as high school completion, college matriculation, and college graduation (Cook and Moore 1993; Yamada, Kendix, and Yamada 1996; Bray et al. 2000; Koch and Ribar 2001; Dee and Evans 2003). Early studies found that alcohol use is associated with reduced educational attainment, either through a reduced probability of graduating (either high school or college) or through a direct negative relationship with the years of schooling completed. More recent work (e.g., Koch and Ribar 2001; Dee and Evans 2003), however, has questioned this finding and suggests a modest negative effect of alcohol use on educational attainment, if there is any effect at all.

The relatively consistent finding that alcohol use is associated with reduced educational attainment, combined with the early focus of the alcohol-wage literature on human capital, has led some authors (e.g., Cook and Moore 2000) to conclude that the effect of alcohol use on wages is mediated through human capital accumulation. This conclusion, however, has remained largely untested in the theoretical and empirical literature. Kenkel and Wang (1999) examined the relationship between alcohol abuse and occupational attainment but did not explicitly link alcohol use while in school to future wages. Bryant et al. (2000) estimated interaction effects between current alcohol use and the wage return to education, but this explored the role of alcohol in the use of a given stock of human capitalthey did not allow alcohol use to affect the accumulation of human capital, as suggested by Cook and Moore. Wolaver (2002) examined the effect of alcohol use on students' grades and found that those who use alcohol have lower grades than those who do not, possibly supporting the conclusion that alcohol has adverse effects on human capital formation. However, she did not directly link this decline in grades to future wages, so the role of human capital formation in the alcohol-wage relationship remains untested.

No study published to date has attempted to isolate human capital formation as the specific causal mechanism linking alcohol use to wages. One potential causal mechanism advanced by the earlier literature and adopted by later studies (Cook and Moore 1993, 2000; Mullahy and Sindelar 1993; French and Zarkin 1995; Bray et al. 2000; Dee and Evans 2003 ) is that the physiological effects of alcohol impair a student's ability 
to learn. This diminished capacity to learn causes people who drink to learn less for any given year of schooling. Thus, alcohol use reduces the efficiency of any given year of schooling in forming human capital and therefore reduces the wage return to that year of schooling. Although much of the previous literature has relied on this hypothesized causal mechanism either implicitly or explicitly, no study has formally incorporated it into a model of wage determination to derive and empirically test a theoretically meaningful relationship between alcohol use, human capital accumulation, and wages.

\section{Theoretical Framework}

To incorporate alcohol use into a model of wage determination, consider a multiperiod model in which wages in period $t$ are determined by the following equation:

$$
\ln \left(w_{t}\right)=\beta_{0}+\beta_{1} X_{t}+\beta_{2} K_{t}+\beta_{3} H_{t}+\xi_{t} .
$$

Equation (1) states that the wage an individual can earn in period $t, w_{t}$, is a function of individual characteristics. These characteristics include $X_{t}$, a set of observable individual demographic characteristics affecting the wage rate; $K_{t}$, the stock of human capital at the beginning of period $t ; H_{t}$, the health stock at the beginning of period $t$; and $\xi_{t}$, an error term capturing unobservable individual characteristics, such as motivation. Equation (1) is based on the standard human capital earnings function (Willis 1992). Additional wage determinants suggested by later literature have been intentionally omitted to focus attention on the human capital term. In a more general model, $H_{t}$ could be viewed as a composite characteristic capturing all omitted wage determinants that are correlated with alcohol use.

For the sake of modeling simplicity, assume that all human capital is homogeneous and that there is no human capital depreciation. Alcohol use affects human capital accumulation by affecting the cognitive and psychomotor abilities necessary to learn new skills. Equation (2) describes the relationship between the stock of human capital $\left(K_{t}\right)$, schooling $\left(s_{t}\right)$, labor market experience $\left(l_{t}\right)$, and alcohol use $\left(a_{t}\right)$ :

$$
K_{t}=K_{t-1}+k\left(s_{t-1}, l_{t-1}, a_{t-1}\right)=K_{0}+\sum_{j=0}^{t-1} k\left(s_{j}, l_{j}, a_{j}\right) .
$$

Equation (2) states that the stock of human capital that an individual has at the beginning of period $t$ is equal to the stock he had at the beginning of period $t-1$ plus the human capital produced in period $t-1$. The human capital production function, $k(\cdot)$, is a function of schooling, work experience, and alcohol use in period $t-1$. By recursing human capital 
back to the initial period, an individual's stock of human capital can be expressed as the sum of each period's production plus the initial stock.

Similar to that of human capital, the accumulation of the health stock can be described by the following equation:

$$
H_{t}=H_{t-1}+b\left(m_{t-1}, a_{t-1}\right)=H_{0}+\sum_{j=0}^{t-1} b\left(m_{j}, a_{j}\right)
$$

where $m_{t}$ is a composite good reflecting all inputs to the health production function other than alcohol. Alcohol enters the health production function to capture any possible health effects of alcohol use.

Taking a first-order Taylor series expansion of $k$ around a fixed point $(\bar{s}, \bar{l}, \bar{a})$ and of $b$ around a fixed point $(\bar{m}, \bar{a})$, substituting the results into equations (2) and (3), and substituting those results into equation (1) yields the following wage equation:

$$
\begin{aligned}
\ln \left(w_{t}\right)= & \beta_{0}+\beta_{1} X_{t}+\beta_{2} K_{0}+\beta_{3} H_{0} \\
& +\delta_{1}(t-1)+\delta_{2} \sum_{j=1}^{t-1} s_{j}+\delta_{3} \sum_{j=1}^{t-1} l_{j} \\
& +\delta_{4} \sum_{j=1}^{t-1} m_{j}+\delta_{5} \sum_{j=1}^{t-1} a_{j}+\varepsilon_{t j},
\end{aligned}
$$

where $\delta_{5}=\beta_{2} k_{a}(\bar{s}, \bar{l}, \bar{a})+\beta_{3} h_{a}(\bar{m}, \bar{a}), k_{a}$ and $b_{a}$ denote the derivative of the human capital and health production functions with respect to alcohol use, and all other terms are as defined in appendix A.

A key feature of equation (4) is that alcohol use enters the wage equation through two different mechanisms: human capital and health. This can be seen in the $\delta_{5}$ coefficient. In addition, if the marginal product of alcohol in forming human capital $\left(k_{a}(\cdot)\right)$ and in forming health $\left(b_{a}(\cdot)\right)$ have the same sign, then $\delta_{5}$ will overestimate the effect of cumulative past alcohol use on human capital accumulation. If they have opposite signs, then $\delta_{5}$ will underestimate the effect of alcohol on human capital accumulation. It is even possible that the human capital and health effects of alcohol use almost completely offset each other such that $\delta_{5}$ is approximately zero. If causal mechanisms other than human capital or health also link alcohol use to wages, then the interpretation of $\delta_{5}$ is even more complicated because it will embody all possible causal mechanisms. Thus, simply estimating the effect of lifetime alcohol use on wages provides no definitive evidence of an effect of alcohol use on human capital accumulation. Another important feature of equation (4) is that the stock of lifetime alcohol use $\left(\sum_{j=1}^{t-1} a_{j}\right)$ rather than current alcohol use enters the wage equation (although current use could potentially enter if it has direct productivity effects).

If the human capital production function is approximated with a sec- 
ond-order Taylor series expansion instead of a first-order Taylor series expansion and substituted appropriately, the following wage equation is derived: ${ }^{1}$

$$
\begin{aligned}
\ln \left(w_{t}\right)= & \beta_{0}+\beta_{1} X_{t}+\beta_{2} K_{0}+\beta_{3} H_{0} \\
& +\gamma_{1}(t-1)+\gamma_{2} \sum_{j=1}^{t-1} s_{j}+\gamma_{3} \sum_{j=1}^{t-1} l_{j}+\gamma_{4} \sum_{j=1}^{t-1} m_{j} \\
& +\gamma_{5} \sum_{j=1}^{t-1} a_{j}+\gamma_{6} \sum_{j=1}^{t-1} s_{j} a_{j}+\gamma_{7} \sum_{j=1}^{t-1} l_{j} a_{j}+\gamma_{8} \sum_{j=1}^{t-1} s_{j} l_{j} \\
& +\gamma_{9} \sum_{j=1}^{t-1} s_{j}^{2}+\gamma_{10} \sum_{j=1}^{t-1} l_{j}^{2}+\gamma_{11} \sum_{j=1}^{t-1} a_{j}^{2}+\varepsilon_{t},
\end{aligned}
$$

where $\gamma_{6}=\beta_{2} k_{s a}(\bar{s}, l, \bar{a}), \gamma_{7}=\beta_{2} k_{l a}(\bar{s}, l, \bar{a})$, and all other terms are as defined in appendix A.

The coefficients on the cumulative alcohol interaction terms, $\gamma_{6}$ and $\gamma_{7}$, measure the differential wage return to education and experience acquired in years in which the individual drank alcohol. They isolate the effect of alcohol use on the marginal human capital product of schooling and experience, respectively. Term $\gamma_{6}$ is the product of the wage return to human capital, $\beta_{2}$, and the effect of alcohol use on the marginal human capital product of schooling, $k_{s a}(\bar{s}, l, \bar{a})$. Term $\gamma_{6}$ captures the effect of alcohol use on the wage returns to education. If we assume that human capital is positively related to wages (i.e., $\beta_{2}>0$ ), then the sign of $\gamma_{6}$ is determined by the sign of $k_{s a}(\bar{s}, l, \bar{a})$. If alcohol use reduces the efficiency of education in the production of human capital, then there will be a lower return to education acquired in those years with alcohol use than in those years without, and $\gamma_{6}$ will be negative. However, if alcohol use has no effect on the efficiency of human capital production, then it will have no effect on the marginal human capital product of schooling, and $\gamma_{6}$ will equal zero. Similarly, term $\gamma_{7}$ is the product of $\beta_{2}$ and the effect of alcohol use on the marginal human capital product of experience $\left[k_{l a}(\bar{s}, l, \bar{a})\right]$, and it captures the effect of alcohol use on the wage returns to experience.

Although $\gamma_{2}, \gamma_{8}$, and $\gamma_{9}$ are coefficients on terms that involve all periods of schooling, they can be interpreted as capturing the return to education in periods in which the individual did not drink alcohol. To see this, consider taking the derivative of equation (5) with respect to schooling in period $t\left(s_{t}\right)$ while holding alcohol use in the same period $\left(a_{t}\right)$ constant at zero to derive the wage return to an additional unit of education.

${ }^{1}$ For simplicity, the first-order Taylor series expansion of the health production function is used. As discussed by Bray (2000), using the simpler first-order expansion for the health production function does not affect our ability to identify the effect of alcohol use on human capital accumulation. 
Holding all else constant, the wage return to one additional unit of education acquired during a period in which the individual does not drink is $\gamma_{2}+\gamma_{8}+\gamma_{9} ; a_{t}$ is zero, and so the interaction $s_{t} a_{t}$ is also zero and $\gamma_{6}$ does not enter. However, the wage return to an additional period of education acquired during a period in which the individual drinks one unit of alcohol is $\gamma_{2}+\gamma_{8}+\gamma_{9}+\gamma_{6}$. Thus, $\gamma_{2}, \gamma_{8}$, and $\gamma_{9}$ represent the returns to schooling for periods in which alcohol is not consumed. Similarly, $\gamma_{3}, \gamma_{8}$, and $\gamma_{10}$ represent the wage return to an additional period of experience in which the individual does not drink.

The term $\gamma_{4}$ represents the wage returns to the composite health input and is the product of the wage return to health $\left(\beta_{3}\right.$ in eq. [1]) and derivatives of the health production function. Terms $\gamma_{5}$ and $\gamma_{11}$ represent the returns to alcohol and commingle the health and human capital effects of alcohol use (see app. A).

In addition to providing a rigorous economic interpretation, equation (5) has considerable intuitive appeal. It shows that the effects of alcohol use on the wage returns to education and experience can be isolated by simply accumulating two types of years of education and experience: those in which individuals drank alcohol and those in which they did not. Thus, equation (5) provides a direct test of the assumption underlying much of the alcohol-wage and alcohol-schooling literature: that the physiological effects of alcohol reduce an individual's ability to form human capital.

Equation (1) captures the fundamental relationship between wages and human capital as suggested by the labor economic literature on wage determination (see, e.g., Willis 1992; Card 1999). As such, it drives much of the theoretical development that led to equation (5). Equation (1) could, however, be extended to allow other factors to influence wages, such as a direct effect of current alcohol use or an interaction between current alcohol use and human capital. As mentioned previously, $H_{t}$ can be viewed as a composite wage determinant that captures any additive term omitted from equation (1), such as current alcohol use reflecting a direct productivity effect. Even determinants that are only weakly separable from human capital, such as interactions with the human capital stock, will not alter the interpretation of equation (5) unless they eliminate the direct effect of human capital from the model. As long as such a direct effect exists, the human capital stock can still be approximated with a secondorder Taylor series expansion, and so equation (5) will still be obtained.

\section{Data and Empirical Model}

\section{A. Data}

Estimating equation (5) requires a data set that includes the educational and alcohol consumption decisions of individuals, as well as their postschooling wages. The 1979 cohort of the National Longitudinal Survey 
of Youth (NLSY; Center for Human Resource Research 1995) is perhaps the only publicly available, nationally representative data set that meets these criteria (GAO 1991; Cook and Moore 2000). The NLSY was originally designed to follow young adults through their first years in the labor market, and the first wave was conducted in 1979 with a total of 12,686 youth aged $14-22$. The NLSY has followed these individuals every year with more than $89 \%$ of the original sample still involved as of 1994 . The 1982-85, 1988, and 1989 NLSY questionnaires asked individuals about their alcohol consumption.

\section{B. Empirical Model}

Because the alcohol use of NLSY respondents is reported only in the years 1982-85, 1988, and 1989, the alcohol use interaction variables needed for the analysis are available only in the years 1983-86, 1989, and 1990. For this reason, the wage equation is estimated for the 10 years beginning in 1983 and ending in 1992. Furthermore, to distinguish the returns to education and experience for years in which respondent's alcohol use is known from those years in which it is not, years of education and experience are accumulated separately for those years in which the respondent's alcohol use is known (1982-85, 1988, and 1989) versus those years in which alcohol use is not known. By accumulating these stocks separately, we can assess the differential wage return for years of education and experience in which the respondent drank alcohol relative to years in which he did not drink alcohol while controlling for the education obtained in years in which the respondent's alcohol use is unknown.

Given these data limitations, the empirical counterpart of equation (5) is specified with the following wage equation:

$$
\begin{aligned}
\ln \left(w_{i t}\right)= & \beta_{w 0}+\beta_{w 1} \operatorname{EDDKN}_{i t}+\beta_{w 2} \mathrm{EDKNW}_{i t}+\beta_{w 3} \mathrm{EXPDKN}_{i t} \\
& +\beta_{w w} \mathrm{EXPDKN}_{i t}+\beta_{w 5} \mathrm{EXPKNW}_{i t}+\beta_{w w 6} \mathrm{EXPKNW}_{i t} \\
& +\beta_{w 7} \mathrm{DRK}_{i t}+\beta_{w s} \mathrm{HVY}_{i t}+\beta_{w 9} \mathrm{EDDRK} \\
& +\beta_{w 10} \mathrm{EDHVY}+\beta_{w 11}{\mathrm{EXPDRK}+\beta_{w 12} \mathrm{EXPHVY}}+\beta_{w 13} \operatorname{deg}_{i t}+\beta_{\mathrm{w} 14} \boldsymbol{x}_{i t}+u_{w i t},
\end{aligned}
$$

where the $i t$ subscript refers to the $i$ th individual in year $t, w_{i t}$ is the wage, and $\boldsymbol{x}_{i t}$ is a vector of demographic and labor market characteristics, which are described below. The $\beta$ s are coefficients to be estimated, and $u_{w i t}$ is an error term whose distribution is specified below.

The term $\mathrm{EDDKN}_{i t}$ is the accumulated years of education in years in which respondents' alcohol use is unknown (1979-81, 1986, 1987, and 1990-92), and the term $\mathrm{EDKNW}_{i t}$ is the accumulated years of education in years in which alcohol use is known (1982-85, 1988, and 1989). The 
term $\mathrm{EDDKN}_{i t}$ and $\mathrm{EDKNW}_{i t}$ sum to the total years of education obtained by the individual and so represent mutually exclusive groups. Similarly, EXPDKN $\mathrm{N}_{i t}$ is the accumulated years of work experience in which alcohol use is unknown, and $\mathrm{EXPKNW}_{i t}$ is the accumulated years of work experience in which alcohol use is known, and thus the two also represent mutually exclusive groups. Terms EXPKNW $2_{i t}$ and EXPDKN $2_{i t}$ are the accumulated squared years of work experience in years in which alcohol use is and is not known, respectively. The term $\mathrm{DRK}_{i t}$ is the accumulated years in which the respondent drank, and $\mathrm{HVY}_{i t}$ is the accumulated years in which the respondent drank heavily.

The years of education and experience for which drinking is known are further separated into years in which the respondent drank and in which the respondent drank heavily. The term EDDRK $_{i t}$ is the accumulated interaction of school enrollment with the indicator for drinking, and the term $\mathrm{EDHVY}_{i t}$ is the accumulated interaction of school enrollment with the indicator for heavy drinking. Similarly, terms EXPDRK $_{i t}$ and EXPHVY $_{i t}$ are the accumulated experience/alcohol use interactions. Vector $\mathbf{d e g}_{i t}$ is a set of degree indicator variables to capture shifts in the returns to education associated with college versus high school education.

Terms $\beta_{w}, \beta_{w 10}, \beta_{w 11}$, and $\beta_{w 12}$ are the primary coefficients of interest and measure the differential return to education or experience associated with alcohol use (relative to years in which the individual did not drink). Because substantial evidence suggests a potential for a differential effect of alcohol use versus alcohol abuse on human capital accumulation and on health (Parker and Nobel 1977; Parker et al. 1983; Hannon et al. 1985; Carey and Maisto 1987; Dufour and Fe Caces 1993; Doll 1998; Elias et al. 1999), equation (6) distinguishes simple or moderate alcohol use from heavy use. Term $\beta_{w}$ is the differential return to education associated with drinking (relative to no consumption), and $\beta_{w 10}$ is the additional increment to the returns to education associated with heavy drinking (relative to any consumption). Similarly, term $\beta_{w 11}$ is the increment to the returns to experience associated with drinking, and term $\beta_{w 12}$ is the additional increment associated with heavy drinking. More formally, these coefficients measure the effect of alcohol use on the human capital productive efficiency of schooling and labor market experience. If alcohol use reduces the return to education (experience), then $\beta_{w 9}$ and $\beta_{w 10}\left(\beta_{w 11}\right.$ and $\left.\beta_{w 12}\right)$ will be negative. If alcohol use increases the return to education (experience), then $\beta_{w 9}$ and $\beta_{w 10}\left(\beta_{w 11}\right.$ and $\left.\beta_{w 12}\right)$ will be positive.

Term $\beta_{w 1}$ is the return to education in general, irrespective of alcohol consumption. Recall that, all else equal, the return to education for years in which we know an individual did not drink alcohol is $\beta_{w 2}$, whereas the return to education for a year in which we know the individual drank alcohol (but not heavily) is $\beta_{w 2}+\beta_{w 9}$. Similarly, terms $\beta_{w 3}$ and $\beta_{w 4}$ measure the return to experience in general (irrespective of alcohol use), and terms 
$\beta_{w s}$ and $\beta_{w 6}$ measure the return to experience for years in which the respondent did not drink alcohol. Terms $\beta_{w 4}$ and $\beta_{w 6}$ are quadratic terms on labor market experience. If labor market experience has a diminishing marginal product in the formation of human capital, then both terms will be negative.

Equation (5) suggests that the accumulated squared years of education (i.e., the sum of the squared years of education, not the square of the sum of years of education) should also be included in equation (6). However, as discussed below, the education stock is measured by accumulating a simple enrollment indicator, and so the squared education terms are identically equal to the linear education terms. As discussed in Bray (2000), the omission of the squared education terms in equation (6) does not alter the general interpretation of terms $\beta_{w 2}$ and $\beta_{w 3}$ (the coefficients on the main education terms) as the returns to schooling, nor does it alter the interpretation of the other coefficients in the model. Equation (5) also includes the accumulated interaction of education and work experience. Because education and work experience are mutually exclusive by construction in this analysis (see below), their interaction is always zero, and so the interaction is dropped from the empirical specification. As with schooling, because alcohol use is measured with simple indicator variables, the squared alcohol use variable is equal to the original alcohol use variable and so is dropped from equation (6). Finally, equation (5) also includes the accumulated composite health input $\left(m_{t}\right)$. Because the NLSY does not contain a suitable proxy for the composite health input, it is omitted from equation (6) and is therefore captured in the error term.

\section{Endogeneity and Sample Selection}

Two important issues need to be considered when estimating equation (6) in order to obtain unbiased parameter estimates of $\beta_{w 9}, \beta_{w 10}, \beta_{w 11}$, and $\beta_{w 12}$ : endogeneity and sample selection. Endogeneity potentially arises in the model because the error term in equation (6) includes the unobserved stock of the composite health input ( $m_{t}$ from eq. [5]), which is likely correlated with the accumulated years of schooling, work experience, and drinking. Sample selection arises because wages are only observed for those individuals who are working and who are not enrolled in school. Both the enrollment and work decisions are choices made by the individual, and so the wage equation sample is self-selected.

To control for both endogeneity and sample selection, this article uses a semiparametric maximum likelihood technique known as the discrete factor method (DFM) that was first proposed by Heckman and Singer (1984) and further developed by Mroz (1999). The DFM technique approximates the distribution of the unobserved heterogeneity that is at the heart of both endogeneity and sample selection with a multivariate discrete distribution. 
The parameters of this distribution are estimated as parameters of the likelihood function. The DFM is a random effects estimator that empirically models all endogenous variables and selection mechanisms.

To provide an intuition of how DFM models the joint distribution of the outcomes, it is useful to think of the multivariate discrete distribution as a histogram. The height of each bar in the histogram is estimated as a probability weight, and the location of each bar in the histogram is estimated as a mass point. The histogram of the error term in one equation is linked to the histogram of the error term in another equation by restricting the two histograms to share a common set of probability weights. The locations of the histogram bars (i.e., the values of the mass points), however, are allowed to vary freely across equations. This analysis allows for two types of unobserved heterogeneity, one that is constant over time within an individual and one that varies over time and individuals.

The empirical approach models the accumulation of the stocks in equation (6). This includes modeling the level of the education stock in the first time period and the accumulation of years of education, work experience, and alcohol use by modeling the enrollment, work, and alcohol use decisions of individuals in all time periods. The two selection processes that affect wages in the model are the decision to be enrolled in school and the decision to work. The accumulation of all stocks and both selection processes are modeled using semi-reduced form equations, with discrete outcomes modeled as logits. Appendix B presents the full likelihood function. The semi-reduced-form equations are auxiliary estimating equations designed to capture the correlation of the alcohol, work, and schooling decisions of youth with the error term in the wage equation. They have not been specified as theoretically meaningful equations and therefore should not be directly interpreted. For this reason, parameter estimates from the DFM auxiliary equations are not presented here but are available upon request.

\section{Analysis Sample}

The NLSY consists of a nationally representative random sample and oversamples of blacks, Hispanics, poor whites, and members of the military. This article uses a sample composed of men from the youngest four cohorts of the NLSY (i.e., those who were aged 14-17 in 1979). This data set includes 14 years (1979-92) of data on the 2,425 males in the nationally representative samples and in the black and Hispanic oversamples. The analysis is limited to males because previous research has shown that males and females differ significantly in their labor supply, schooling, and alcohol use patterns (Mroz 1987; Killingsworth and Heckman 1992; Mullahy and Sindelar 1992, 1996). The analysis is limited to the youngest four cohorts so that it includes observations on schooling decisions during the 
years $1982-85$, the time when the NLSY asked about alcohol use. Data on males in the nationally representative samples and in the black and Hispanic oversamples are included based on the recommendations in MaCurdy, Mroz, and Gritz (1998).

In addition, observations on person years that have missing values for school enrollment or alcohol use, that correspond to noninterviews, or in which an individual reports being in the military were eliminated for this analysis. Once an individual is dropped from the analysis sample in a given year, he is dropped from all subsequent years as well (for an analysis of attrition in the NLSY, see MaCurdy et al. [1998]). Less than $2 \%$ of all omitted person years are lost due to missing data. The final analysis sample includes 26,518 person years on 2,423 individuals.

\section{E. Variable Definitions}

Following MaCurdy et al. (1998), wages are measured as average hourly earnings. The average hourly wage is calculated by dividing the total annual income from wages and salary before taxes by the number of hours worked in the year. The natural log of the average hourly wage is used in the analysis, and the log wage is set to missing if the individual was enrolled in school. All wages have been adjusted to 1982-84 dollars using the Consumer Price Index (CPI) for all urban consumers. To minimize the effect of outliers, wages are set to missing if they are less than \$2 an hour or more than $\$ 200$ an hour.

The education stock in years after 1979 is accumulated based on the enrollment status of the respondent as of May 1 of the interview year. The highest grade completed in 1979 corresponds to the highest grade completed as of May 1, 1979. Labor market experience is measured by summing the hours worked over years in which the individual was not enrolled in school and dividing this sum by 2000 . Hours of work are measured using the total hours worked in the past year. Years of experience are assumed to be zero until age 17. Alcohol use in 1982-85, 1988, and 1989 is measured by two indicator variables measuring whether the respondent reported drinking in the past month or drinking heavily in the past month (i.e., had six or more drinks on three or more occasions in the past month). These alcohol use variables are interacted with the school enrollment status indicator and with hours of work in each applicable year to capture years of education or experience in which the respondent drank or drank heavily. These interactions are then accumulated over time to create the interaction stocks implied by equation (5) and included in equation (6) as the variables $\mathrm{EDDRK}_{i t}, \mathrm{EDHVY}_{i t}, \mathrm{EXPDRK}_{i t}$, and $\mathrm{EXPHVY}_{i t}$.

The following variables are included as demographic characteristics affecting the wage rate: age, the Armed Forces Qualification Test Score 
(AFQT), race, region, and unemployment rate. Age is measured with indicator variables for the respondent's 1979 age cohort, continuous age in each year divided by 10 , continuous age squared in each year divided by 100 , and the number of years since 1979 squared divided by 100 .

As discussed below, the estimation technique employed in this article requires the use of identifying instruments that explain the initial human capital stock and the enrollment, work, and alcohol use decisions but that do not directly affect wages. Following previous literature on the returns to education (Ashenfelter and Zimmerman 1997; Conneely and Uusitalo 1997; Card 1999), this article uses a set of demographic characteristics that describe the individual's family background as of age 14 as identifying instruments for the initial human capital stock. These variables include the working status of the adults in the respondent's household at age 14, parents' education, the respondent's family structure at age 14, and the religion the respondent was raised in. For identifying instruments for the enrollment, work, and alcohol use decisions, data on state-level beer tax, cigarette tax, minimum legal drinking age (MLDA), and government educational expenditures were merged with the NLSY data to serve as additional wage exclusion restrictions. ${ }^{2}$ All price, tax, and expenditure variables have been adjusted to 1982-84 dollars using the CPI for all urban consumers, and missing values for exogenous variables were imputed using the methods described in Bray (2000).

\section{F. Identification}

Identification of the parameters in the wage equation is achieved through two mechanisms: exclusion restrictions and the use of longitudinal data. Wages do not depend directly on the family background variables because employers do not observe them, but the initial education stock does depend on these variables. Therefore, these variables serve as exclusion restrictions that help to identify the parameters of the wage equation. Furthermore, wages do not depend directly on the policy variables, but schooling demand, alcohol demand, and labor supply do. Thus, both the current and lagged policy vectors also serve as exclusion restrictions that identify the parameters of the wage equation. As discussed in Mroz and Surette (1998), all policies in all years serve as exclusion restrictions, thus dramatically increasing the number of exclusion restrictions. In addition to the exclusion restrictions, identification is also achieved through the use of longitudinal data. To the extent that the unobserved heterogeneity is constant over time, changes over time within an individual help to identify the wage equation.

\footnotetext{
${ }^{2}$ I am grateful to Frank Chaloupka and Rosalie Pacula for the beer tax and MLDA data. Matthew Farrelly kindly provided the cigarette tax data, and Alex Cowell provided the educational expenditure data.
} 


\section{Results}

Table 1 presents unweighted descriptive statistics for all variables as measured in a representative year, 1985 (1985 allows the observation of 3 previous years of drinking experience, yet about one-fifth of the sample are still enrolled in school). The average years of education in which respondents' drinking is not known in 1985 is 11.4 years, and the average years of education in which drinking is known is 1.2. On average, approximately 0.8 years of education were obtained in years in which the respondent drank and 0.2 in which he drank heavily. These averages are not surprising given that we have only observed 3 years of drinking behavior and that most individuals do not begin drinking until their later years of schooling. About $80 \%$ of the sample have at least 12 years of education, and $9 \%$ have 16 or more years of education. About $75 \%$ of respondents drank alcohol, and $15 \%$ drank heavily in 1985 . About $80 \%$ of the nonenrolled sample were employed (i.e., had an observed wage) in 1985. Those who were employed earned an average wage of $\$ 6.21$ and worked an average of 1,949 hours. In 1985, individuals had an average of 0.2 years of work experience in years in which drinking is not known and 1.2 years of experience in which drinking is known. The average years of experience in which the individual drank is 0.9 years, and the average years in which the individual drank heavily is 0.3 years.

By 1985, the average age of the sample is almost 22 years old. The analysis sample is predominately white and is fairly evenly spread over regions, with the South being the most prevalent. The average local area unemployment rate in 1985 is $8.13 \%$. Just over half of the sample in 1985 had a female working in their household at age 14 , and almost $75 \%$ had a male working in their household at age 14 . The average highest grade completed by the father was just under 11 years, whereas the highest grade completed by the mother was just over 11 years. Almost $80 \%$ of the sample lived with two parents at age 14 . The majority of the sample was raised as either Catholic or Baptist. The average state expenditures on postsecondary education per postsecondary student were approximately $\$ 630$, whereas the expenditures per secondary student averaged $\$ 350$. By 1985 , the majority of the sample was older than the MLDA. Approximately $39 \%$ of the sample lived in a state where the MLDA for beer was 21 in 1985, and about 57\% lived in a state where the MLDA for liquor was 21 . Finally, the real taxes were $\$ 0.47$ on cigarettes and $\$ 0.52$ on beer.

Before estimating the DFM model, the adequacy of the identifying instruments was assessed using a two-stage least squares (2SLS) model. Staiger and Stock (1997) discuss problems with 2SLS arising from weak instruments (i.e., instruments that perform poorly in the first stage regressions). In addition to resulting in imprecise and potentially biased 
Table 1

Summary Statistics of Variables for All Respondents in 1985

\begin{tabular}{|c|c|c|}
\hline Variable & Mean & Standard Deviation \\
\hline \multicolumn{3}{|l|}{ Education measures: } \\
\hline Years of education in which drinking is not known & 11.417 & 1.395 \\
\hline Years of education in which drinking is known & 1.237 & 1.222 \\
\hline Years of education in which drank any & .802 & 1.081 \\
\hline Years of education in which drank heavily & .225 & .597 \\
\hline 12 years of education or more & .797 & .402 \\
\hline 16 years of education or more & .090 & .286 \\
\hline \multicolumn{3}{|l|}{ Work experience: } \\
\hline Years of experience in which drinking is not known & .235 & .536 \\
\hline Years of experience in which drinking is known & 1.173 & 1.231 \\
\hline Years of experience in which drank any & .916 & 1.135 \\
\hline Years of experience in which drank heavily & .303 & .691 \\
\hline \multicolumn{3}{|l|}{ Alcohol use measures: } \\
\hline Cumulative past month drinking & 2.100 & 1.112 \\
\hline Cumulative heavy drinking & .657 & .949 \\
\hline \multicolumn{3}{|l|}{ Employment: } \\
\hline Currently enrolled & .221 & .415 \\
\hline Employed & .798 & .401 \\
\hline Average hourly real wage (1982-84 dollars) & 6.214 & 4.237 \\
\hline \multicolumn{3}{|l|}{ Demographic controls in the wage equation: } \\
\hline Age & 21.615 & 1.068 \\
\hline Detrended AFQT & .365 & 23.974 \\
\hline \multicolumn{3}{|l|}{ Race: } \\
\hline White & .495 & .500 \\
\hline Black & .305 & .461 \\
\hline Hispanic & .200 & .400 \\
\hline \multicolumn{3}{|l|}{ Geographic location: } \\
\hline Northeast & .183 & .386 \\
\hline North Central & .240 & .427 \\
\hline West & .207 & .405 \\
\hline South & .368 & .482 \\
\hline Urban area & .771 & .420 \\
\hline Local area unemployment rate & 81.339 & 30.061 \\
\hline \multicolumn{3}{|l|}{ Wage equation exclusion restrictions: } \\
\hline Working female in household at age 14 & .555 & .495 \\
\hline Working male in household at age 14 & .742 & .436 \\
\hline Highest grade completed by father & 10.917 & 3.985 \\
\hline Highest grade completed by mother & 11.005 & 3.194 \\
\hline Lived with two parents at age 14 & .792 & .406 \\
\hline Raised as Baptist & .285 & .450 \\
\hline Raised as Catholic & .347 & .475 \\
\hline Raised as Protestant & .222 & .415 \\
\hline Raised in other religion & .145 & .351 \\
\hline \multicolumn{3}{|l|}{ State real postsecondary education expenditures per } \\
\hline postsecondary student $(\$ 1,000)$ & .628 & .105 \\
\hline $\begin{array}{l}\text { State real secondary education expenditures per second- } \\
\text { ary student }(\$ 1,000)\end{array}$ & .354 & .086 \\
\hline Respondent older than minimum legal drinking age & .919 & .272 \\
\hline State minimum legal drinking age for beer less than 21 & .385 & .487 \\
\hline State minimum legal drinking age for liquor less than 21 & .566 & .496 \\
\hline Real cigarette tax & .473 & .089 \\
\hline Real beer tax & .517 & .596 \\
\hline
\end{tabular}

Note. - All dollar-denominated variables have been adjusted to 1982-84 dollars. $N=1,884$, except for the variables Employed, where $N=1,467$, and Average hourly real wage (1982-84 dollars), where $N=$ 1,171 . 
2SLS estimates, weak instruments may also bias some variants of standard tests for overidentification and exogeneity. The first step in assessing the strength of the identifying instruments is to examine their performance in the first stage regression of a 2SLS model. For the 2SLS model, all of the education, work experience, and alcohol stock variables are treated as endogenous. This includes the degree indicators for a total of 14 endogenous variables. The identifying instruments used for 2SLS are the family background variables and the state-level tax, MLDA, and government educational expenditure variables. To better approximate the dynamic identification strategy of the DFM approach, one-period lags of the tax and educational expenditure variables were also used as identifying instruments.

Using ordinary least squares (OLS) regression with robust standard errors to adjust for repeated observations on individuals, the identifying instruments are jointly significant at the 0.01 level or better in all first stage equations. ${ }^{3}$ Given the dynamic structure of the DFM approach, it is important to assess the significance of the time-varying instruments (i.e., the tax and educational expenditure variables) separately from the time-invariant instruments (i.e., the family background variables). Using the same OLS regressions, the price and expenditure variables (and their lags) were jointly significant at 0.01 level or better in nine of the 14 firststage equations and significant at the 0.05 level in another three first-stage equations. If the probability of a Type II error was $20 \%$ (i.e., power of .8 ), then we should expect three out of 14 tests to fail to reject a false null by chance alone. Thus, it appears that both the family background variables and the state-level policy variables perform adequately in the first stage regressions.

Next, a Hansen J test for overidentification (Baum, Schaffer, and Stillman 2003) was conducted using the 2SLS model. The Hansen J test is a heteroskedasticity-consistent overidentification test that is asymptotically equivalent to the Basmann test and is appropriate for use with clustered data. Staiger and Stock (1997) recommend the Basmann test for use with weak instruments because they find that it tends to overreject the null of overidentification, whereas other tests tend to underreject the null. The Hansen $J$ test failed to reject the null hypothesis that the wage equation exclusion restrictions are valid. As recommended by Staiger and Stock, the 2SLS model was also used to conduct the Durbin form of the Durbin-Wu-

\footnotetext{
${ }^{3}$ Staiger and Stock (1997) suggest an overall summary measure for use with multiple endogenous variables, and Stock and Yogo (2004) provide critical values and asymptotic properties for a similar measure that they refer to as $g_{\min }$. These properties and critical values assume independent observations, however, and this assumption is clearly violated by the longitudinal data used in this analysis. Nonetheless, $g_{\min }$ was calculated and found to exceed the critical value suggested by Stock and Yogo, suggesting that the instruments used in this analysis are "strong."
} 
Hausman test for exogeneity, which rejected the null hypothesis of exogeneity. Based on the results of these tests, we conclude that the overidentifying assumptions are valid and that the alcohol use, education, and work experience variables in the wage equation are endogenous.

Table 2 presents OLS, 2SLS, individual fixed effects (FE), and DFM estimation results for the empirical wage equation described in the previous section. The 2SLS and FE results are presented to allow an assessment of the relative contribution of the identifying instruments and the longitudinal data to the identification of the wage equation. The number of mass points in the DFM model was determined based on upward testing, as suggested by Mroz (1999). The final DFM specification has 14 mass points for the time-constant heterogeneity and 16 mass points for the time-varying heterogeneity. A complete set of DFM results is available upon request.

Looking first at the OLS results in table 2, none of the incremental returns to education or experience acquired in years with drinking are significant, but three are positive. Only the additional incremental return of experience acquired in a year with heavy drinking is negative. These results suggest that alcohol use does not have detrimental effects on the wage returns of either schooling or of experience. The 2SLS results are implausibly large and imprecisely estimated, suggesting that, despite the results from the overidentification testing, the identifying instruments may be weak. The 2SLS results do, however, provide further evidence against a negative relationship between alcohol use and human capital accumulation. The FE results are more plausible than the 2SLS results and generally suggest a bias in the OLS results in the same direction as that suggested by the 2SLS results for the primary coefficients of interest.

In general, the DFM results for the primary coefficients of interest fall in between the OLS and 2SLS/FE results, and although not generally significant they are plausible and correct for the endogeneity bias found by the Durbin-Wu-Hausman test discussed earlier. Importantly, they also correct for any sample selection bias caused by self-selection into the wage equation. If the implausibility and imprecision of the 2SLS results are taken as evidence of weak instruments, then the DFM results should be viewed as the preferred estimates. Mroz (1999) demonstrates that DFM outperforms 2SLS in the presence of weak instruments, and, unlike the FE estimates, they control for time-varying unobserved heterogeneity that might bias the OLS results.

Turning to the DFM results in detail, the estimated general return to education $\left(\beta_{w 1}\right.$ in eq. [6]) is approximately $7 \%$ and is significant at the 0.01 level. This estimate is well within the generally accepted return to education of $5 \%-12 \%$ (Card 1999). The return to education for years in which alcohol is not used ( $\beta_{w 2}$ in eq. [6]) is somewhat lower, at approximately $5 \%$, but it is still significant at the 0.05 level. 
Estimates of the incremental return to education for years in which alcohol was consumed ( $\beta_{w 9}$ and $\beta_{w 10}$ from eq. [6]) are both statistically insignificant but potentially meaningful. Perhaps counter to intuition, the incremental return to years with alcohol use is positive and relatively substantial at approximately $3 \%$. This increment is in addition to the $5 \%$ return for a year of education obtained while not drinking and holds constant the total years of education obtained. The additional increment to the return to education for years with heavy drinking is negative but insignificant. Combined, these results suggest that, holding all else constant, an additional year of education acquired in a period in which alcohol is consumed increases wages by approximately $8.5 \%(0.052+0.033)$. An additional year of education acquired in a year in which alcohol is consumed heavily increases wages by approximately $6.8 \%(0.052+0.033-$ 0.017).

Interpreting these results in terms of parameters from the theoretical wage equation presented in equation (5), they suggest that $\gamma_{6}$ is positive. Recall that $\gamma_{6}$ is the product of the wage return to human capital and the effect of alcohol use on the marginal human capital product of schooling. If we assume a positive relationship between human capital and wages, these results suggest that the effect of alcohol use on the marginal human capital product of schooling is positive, meaning that alcohol use increases the productivity of schooling in forming human capital. The negative effect of heavy drinking, however, suggests a nonlinear relationship between alcohol use and human capital accumulation in which moderate drinking increases human capital accumulation but in which heavier drinking has adverse effects.

Looking at the estimated returns to labor market experience, the linear term for the return to experience in general, irrespective of alcohol use $\left(\beta_{w 3}\right.$ from eq. [6]), suggests an estimated return of approximately $7.5 \%$ that is significant at the 0.01 level. The quadratic term on the return to experience in general ( $\beta_{w 4}$ from eq. [6]) is small, negative, and insignificant. Recall that experience in each year is measured as hours of work divided by 2,000 , so the estimates imply that working an additional 2,000 hours (equivalent to one additional year) increases wages by approximately $5.7 \%$ $(0.075-0.018)$. The return to experience for years without alcohol use $\left(\beta_{w s}\right.$ and $\beta_{w 6}$ from eq. [6]) is less than the return in general. The linear term is positive and significant at the 0.05 level, whereas the quadratic term is small, negative, and insignificant. Taken together, they imply a return to an additional 2,000 hours of experience without alcohol use of approximately $3.3 \%(0.041-0.008)$.

The incremental return to experience for years in which alcohol is consumed is $3.8 \%$ and significant at the 0.05 level. This effect more than doubles the return to experience for years without alcohol use and holds constant the total years of experience and education. Although small and 
Table 2

Log Wage Equation DFM Parameter Estimates

\section{Parameter}

OLS Estimate 2SLS Estimate FE Estimate DFM Estimate

Returns to education:

General return to education, irrespective of alcohol use

Return to education in years without alcohol use

Incremental return to education for years with drinking

Additional incremental return to education for years with heavy drinking

Returns to experience:

General return to experience, irrespective of alcohol use:
Linear term

\section{Quadratic term}

Return to experience in years without alcohol use: Linear term

Quadratic term

Incremental return to experience for years with drinking

Additional incremental return to experience for years with heavy drinking

Age: 15 in 1979

Age 16 in 1979

Age 17 in 1979

Age

\begin{tabular}{|c|c|c|c|}
\hline $\begin{array}{l}.045 \% * \\
(.009) \\
.047 * * \\
(.016) \\
.010 \\
(.021) \\
.007 \\
(.027)\end{array}$ & $\begin{array}{r}-.175 \\
(.364) \\
-.070 \\
(.758) \\
.488 \\
(1.129) \\
.680 \\
(1.710)\end{array}$ & $\begin{array}{c}.099 * * \\
(.024) \\
-.012 \\
(.052) \\
.106^{+} \\
(.059) \\
.024 \\
(.058)\end{array}$ & $\begin{array}{c}.070 * * \\
(.023) \\
.052 * \\
(.032) \\
.033 \\
(.029) \\
-.017 \\
(.037)\end{array}$ \\
\hline $\begin{array}{c}.113 * * \\
(.022) \\
-.052 * * \\
(.016)\end{array}$ & $\begin{array}{c}.351 \\
(1.290) \\
-.261 \\
(1.024)\end{array}$ & $\begin{array}{c}.090 * \% \\
(.021) \\
-.026 * \\
(.013)\end{array}$ & $\begin{array}{c}.075^{* *} \\
(.024) \\
-.018 \\
(.015)\end{array}$ \\
\hline $\begin{array}{c}.096 * * \\
(.022) \\
-.036 * \\
(.015) \\
.021 \\
(.018) \\
-.008 \\
(.022)\end{array}$ & $\begin{array}{r}-.197 \\
(.802) \\
-.128 \\
(.800) \\
.892 \\
(.938) \\
.283 \\
(.765)\end{array}$ & $\begin{array}{c}.058^{* *} \\
(.020) \\
-.016 \\
(.013) \\
.02 \\
(.019) \\
.014 \\
(.023)\end{array}$ & $\begin{array}{c}.041^{*} \\
(.024) \\
-.00 \\
(.012) \\
.038^{*} \\
(.018) \\
-.001 \\
(.019)\end{array}$ \\
\hline $\begin{array}{l}.014 \\
(.032) \\
.034 \\
(.050) \\
.002 \\
(.070) \\
.143 * * \\
.032)\end{array}$ & $\begin{array}{r}-.032 \\
(.253) \\
-.110 \\
(.471) \\
-.145 \\
(.694) \\
(.345 \\
(.325)\end{array}$ & $\begin{array}{l}1.895^{* * *} \\
(.258)\end{array}$ & $\begin{array}{c}-.006 \\
(.095) \\
-.038 \\
(.185) \\
-.112 \\
(.282) \\
1.831 \% \\
(.665)\end{array}$ \\
\hline
\end{tabular}


Age squared

Time squared

Race (reference category is white):
Black

Hispanic

Region (reference category is South):

Northeast

North Central

West

Urban area

Other variables:

Local area unemployment rate

Detrended AFQT

12 years of education or more

16 years of education or more

Cumulative drinking

Cumulative heavy drinking

Intercept

\begin{tabular}{|c|c|c|c|}
\hline $\begin{array}{c}-.003^{* * *} \\
(.001) \\
-.001 \\
(.001)\end{array}$ & $\begin{array}{c}-.004 \\
(.003) \\
-.00 \\
(.005)\end{array}$ & $\begin{array}{c}-.267 * * * \\
(.063) \\
-.378 * * \\
(.093)\end{array}$ & $\begin{array}{c}-.286 \\
(.267) \\
-.27 \\
(.471)\end{array}$ \\
\hline $\begin{array}{c}-.145^{* * *} \\
(.020) \\
-.096^{* * *} \\
(.024)\end{array}$ & $\begin{array}{r}.106 \\
(.397) \\
-.046 \\
(.332)\end{array}$ & & $\begin{array}{c}-.111^{* *} \\
(.029) \\
-.085 * * \\
(.032)\end{array}$ \\
\hline $\begin{array}{l}.106^{* * *} \\
(.023) \\
.006 \\
(.022) \\
.078^{* * *} \\
(.023) \\
.055^{* *} \\
(.018)\end{array}$ & $\begin{array}{l}.123 \\
(.166) \\
.115 \\
(.143) \\
.155 \\
(.196) \\
.038 \\
(.093)\end{array}$ & $\begin{array}{c}.033 \\
(.043) \\
-.126 * \\
(.039) \\
.061 \\
(.041) \\
.025 \\
(.017)\end{array}$ & $\begin{array}{c}.106 * * \\
(.023) \\
-.026 \\
(.023) \\
.060 * * \\
(.022) \\
.054 * ; \\
(.017)\end{array}$ \\
\hline $\begin{array}{c}-.001 * * \\
(.000) \\
.002 * * \\
(.000) \\
-.073 * \\
(.029) \\
.021 * * \\
(.041) \\
-.008 \\
(.017) \\
-.020 \\
(.022) \\
-.557 \\
(.405)\end{array}$ & $\begin{array}{r}.000 \\
(.001) \\
.000 \\
(.007) \\
-.379 \\
(1.474) \\
. .694 \\
(1.716) \\
-. .442 \\
(.568) \\
-. .507 \\
(.976) \\
-1.177 \\
(7.074)\end{array}$ & $\begin{array}{c}.010 \\
(.023) \\
\\
-.068 \\
(.079) \\
.121^{*} \\
(.057) \\
-.015 \\
(.019) \\
-.01 \\
(.024)\end{array}$ & $\begin{array}{c}-.038 \\
(.040) \\
.00 \\
(.001) \\
-.028 \\
(.036) \\
.185 * \\
(.039) \\
-.018 \\
(.021) \\
-.002 \\
(.021) \\
-1.764 * \\
(.809)\end{array}$ \\
\hline
\end{tabular}

$N=11,533$ observations on 1,849 individuals. Standard errors in parentheses. OLS $=$ ordinary least squares method. $2 \mathrm{SLS}=$ two-stage least squares method $\mathrm{E}=$ fixed effects method. DFM = discrete factor method. The OLS and 2SLS standard errors have been adjusted for clustering on the individual. Significantly different from 0 at the $10 \%$ level.

Significantly different from 0 at the $5 \%$ level. 
insignificant, the additional increment for years with heavy drinking is negative, again suggesting a nonlinear relationship between drinking and human capital accumulation. Combined, these results suggest that, holding all else constant, an additional year of experience in which alcohol is consumed increases wages by approximately $7.1 \%(0.041-0.008+$ 0.038). An additional year of experience in which alcohol is consumed heavily increases wages by approximately $7 \%(0.041-0.008+0.038-$ 0.001).

As with the results for education, these estimates suggest that alcohol use increases the productivity of labor market experience in forming human capital. Specifically, the results suggest that $\gamma_{7}$ in equation (5) is positive and imply that the effect of alcohol use on the marginal human capital product of experience is also positive. The small negative coefficient on the additional increment to the returns to experience for years with heavy drinking, however, suggests that this relationship may be nonlinear such that excessive drinking may have detrimental effects.

The remaining estimated coefficients in the wage equation are largely of the expected sign and significance. Of the age variables, only continuous age is significant, and it is positive as expected. Both blacks and Hispanics earn significantly lower wages on average than whites. Individuals in the Northeast and West earn significantly more than those in the South, and individuals in urban areas earn more than those in rural areas. There is a positive and significant degree effect associated with the completion of 16 years of education or more. Interestingly, there is an insignificant negative degree effect associated with the completion of 12 years of education. Although the negative high school degree effect is somewhat unusual, it is consistent with other research that has used an NLSY sample similar to the one used here (e.g., Savage 1999) and is related to the inclusion of both the education stock and the work experience stock. In OLS regressions, if the cumulative years of work experience is dropped from the model, then the coefficient on completing 12 years of education becomes positive. Although small, the effect of AFQT is positive and significant in OLS models but is approximately zero in all models that control for the endogeneity of the human capital stock. This result is consistent with AFQT influencing wages primarily through its effects on educational decisions. Finally, the effects of both alcohol stock variables are negative but insignificant.

As discussed earlier, alternatives to the primary wage equation (eq. [1]) could be hypothesized that would suggest additional variables to be included in the empirical wage equation represented by equation (6). Although the omission of any such variables would not alter the theoretical interpretation of the key parameters of interest, it may bias the estimate of these parameters. To explore this possibility, an augmented equation (6) was estimated using OLS. In addition to variables already in equation 
(6), this augmented equation included current alcohol use (both simple use and heavy use) and interactions between the current alcohol use variables and the total years of education and total years of work experience. Because alcohol use is only observed in 1982-85, 1988, and 1989, the augmented wage equation was estimated only for these years (excluding 1982 to allow the observation of at least one year of alcohol use while in school). The OLS estimates of the parameters of interest were approximately the same as the OLS results presented in table 2. The coefficients on the additional variables were all insignificant and less than 0.01 in absolute value. Based on these results, it appears that the omission of these additional variables does not bias the estimates of the key parameters of interest.

\section{Discussion and Conclusion}

Despite a large body of economic literature on the effect of alcohol use on wages, no previous study has developed and estimated a theoretical model that isolates a single causal mechanism linking alcohol use to wages. This article develops and estimates a theoretical model of wage determination that isolates the effects of alcohol use on wages as mediated through human capital accumulation. Although not generally significant, estimation results suggest that moderate alcohol use has a positive effect on the returns to education or experience, and therefore on human capital accumulation, but that heavier drinking reduces this gain slightly. Based on these results, alcohol use does not appear to adversely affect the returns to education or work experience and therefore has no negative effect on the efficiency of education or experience in forming human capital. Rather, alcohol use appears to be beneficial to human capital accumulation.

Although the general lack of statistical significance suggests that caution be used when drawing conclusions about the magnitude of the effect of alcohol use on human capital accumulation, the estimated incremental returns to education and experience for years with drinking seem substantial when compared to the returns for years without drinking. For example, moderate alcohol use more than doubles the returns to experience. Although these effects may seem large, the returns to education and experience presented in this article, both with and without alcohol use, are well within the generally accepted estimates of the returns to education and experience from the labor economics literature. Furthermore, a majority of individuals appear to receive the higher rates of return associated with alcohol use (over $60 \%$ of the analysis sample consumed alcohol in any given year), suggesting that relatively substantial incremental returns to education and experience for years with moderate drinking are consistent with the observed behavior of individuals.

We can only speculate as to why alcohol use might increase the returns 
to education and experience, but at least two possible causal mechanisms are consistent with the theoretical model derived in this article. First, the social aspects of moderate drinking may improve the efficiency of human capital formation. Investing in human capital through schooling and work experience is at least partly a social activity. Because moderate drinking is the social norm in the United States, moderate alcohol use may improve socialization and therefore lead to greater efficiency in overall human capital production. Second, moderate alcohol use may actually improve cognitive functioning and so increase the efficiency of human capital production. Although studies examining the effect of drinking on cognition have found conflicting results ranging from large negative effects, to no effect, to positive effects of moderate drinking on cognition (Parker and Nobel 1977; Parker et al. 1983; Hannon et al. 1985; Carey and Maisto 1987; Elias et al. 1999), there is at least some evidence that moderate drinking may improve cognitive functioning.

Although the empirical model presented in this article is very different from those used by the previous alcohol-wage literature (e.g., Mullahy and Sindelar 1989; French and Zarkin 1995; Heien 1996), it is still useful to compare the results presented here with those of the previous literature. Much of the previous literature has found a positive relationship between simple alcohol use and wages (e.g., Zarkin et al. 1998), which is broadly consistent with the positive human capital effects found here. Importantly, however, studies finding a positive relationship have usually used measures of current alcohol use rather than the stock of past use measure used here. To interpret these results within the theoretical framework presented in this article, the current use measures must be assumed to proxy for lifetime use.

Other studies have found a negative relationship between chronic alcohol abuse and wages (e.g., Mullahy and Sindelar 1993). The negative incremental returns associated with heavy drinking found in this analysis, combined with the negative effects of the alcohol stock variables, suggest that such a negative relationship may also be consistent with the results presented here. The theory developed in this article shows that results of the previous literature that used measures of chronic alcohol abuse have commingled the human capital and health effects of alcohol use. This article isolated the human capital effects of alcohol use and found them to be positive, but it is possible that there are large negative health effects associated with chronic alcohol abuse that this article has not separately estimated.

Finally, some authors have suggested that the apparently anomalous findings of the previous literature are a result of empirical problems such as endogeneity and sample selection (Cook and Moore 2000). Importantly, this article used an estimation technique that accounted for the endogeneity of alcohol use, school enrollment, and work experience and that 
accounted for sample selection into the wage equation and the bounded nature of the alcohol, schooling, and work decisions. Thus, this is the first article to simultaneously address all of the potential estimation issues involved in estimating the effect of alcohol use on wages as mediated through human capital accumulation. This is also the first article in the alcohol-wage literature to treat educational attainment as endogenous, and so it allows alcohol use to affect both the quality and quantity of education and experience obtained.

In addition to the alcohol-wage literature, the theoretical and empirical results presented in this article also have bearing on the alcohol-schooling literature, even though a structural schooling equation was not estimated. Most studies on the relationship between alcohol use and schooling have found that alcohol use reduces educational attainment (Cook and Moore 2000) and have interpreted this finding to mean that alcohol use adversely affects human capital formation. Bray (2000), however, shows that the alcohol-schooling literature has not isolated the human capital effects of alcohol use from possible contemporaneous substitution effects between alcohol use and leisure that result from alcohol's status as a consumption good. By isolating the human capital effects of alcohol use from any contemporaneous substitution effects, this article provides a useful context within which to interpret the alcohol-schooling literature. Thus, while any detrimental effects of alcohol use on wages may still be mediated through schooling choices, the efficiency of human capital formation does not appear to be the underlying causal mechanism linking alcohol use to both lowered wages and lowered educational attainment.

The results presented here have three limitations that should be noted, however. First, the alcohol consumption variables used in this article cannot isolate drinking that occurs immediately prior to or during school or work. It is this form of drinking that is most likely to cause cognitive impairments that would adversely affect human capital formation, and so we cannot rule out the possibility that contextual alcohol use has adverse effects on human capital formation. Second, past-month drinking was assumed to be indicative of consumption patterns for the whole year. To the extent that the drinking patterns of the survey month are atypical of the entire year, the results could be misleading. Importantly, though, it seems unlikely that past month drinking consistently overstates or understates the true annual drinking rate of every individual. Rather, it is more likely that any error in the measurement of drinking is randomly distributed and therefore the most likely impact on the estimates is to bias them toward zero. Third, we do not observe an individual's entire drinking history, thus limiting the information available to estimate the theoretical model. The empirical model used in this article accommodated this limitation so that this lack of information did not affect our ability 
to identify the effects of interest, but it did potentially reduce the precision of the estimates.

Despite these limitations, this article makes three important contributions. First and foremost, it develops the first theoretical model of wage determination linking alcohol use to wages via human capital accumulation. The model has considerable intuitive appeal that does not depend upon the strength of the empirical estimates. It suggests that the effects of alcohol use on the wage returns to education and experience can be isolated by simply accumulating two types of years of education and experience, those in which individuals drank alcohol and those in which they did not, and it provides a rigorous economic interpretation for the resulting coefficients. The theoretical model also demonstrates that the empirical results of much of the previous alcohol-wage literature cannot be easily interpreted within a human capital framework.

Second, this article shows that alcohol use does not have a negative effect on human capital accumulation. Although the results indicate that heavier drinking slightly reduces the wage returns to education and experience (relative to moderate use), the overall effect of alcohol use on the returns to education and experience was positive but largely insignificant. Third, the theoretical model and empirical strategy used in this article can be easily adapted to examine the future wage effects of a host of other behaviors. In addition to alcohol use, policy makers and social scientists have identified a litany of other behaviors that may have adverse effects on the returns to education. Among these are illicit drug use, gang involvement, and teen employment. Importantly, this article has provided a general and easily adaptable framework within which to examine the effects of these behaviors on the returns to education.

\section{Appendix A}

\section{Parameters of the Theoretical Wage Equations}

This appendix presents definitions of the parameters of the theoretical wage equations derived in the text. Using first-order Taylor series expansions for the human capital and health production functions yields the following wage equation (this is identical to original eq. [4]):

$$
\begin{aligned}
\ln \left(w_{t}\right)= & \beta_{0}+\beta_{1} X_{t}+\beta_{2} K_{0}+\beta_{3} H_{0}+\delta_{1}(t-1) \\
& +\delta_{2} \sum_{j=1}^{t-1} s_{j}+\delta_{3} \sum_{j=1}^{t-1} l_{j}+\delta_{4} \sum_{j=1}^{t-1} m_{j}+\delta_{5} \sum_{j=1}^{t-1} a_{j}+\varepsilon_{t},
\end{aligned}
$$


where

$$
\begin{aligned}
\delta_{1}= & \beta_{2}\left[k(\bar{s}, l, \bar{a})-\bar{s} k_{s}(\bar{s}, l, \bar{a})-l k_{l}(\bar{s}, l, \bar{a})-\bar{a} k_{a}(\bar{s}, l, \bar{a})\right] \\
& +\beta_{3}\left[h(\bar{m}, \bar{a})-\bar{m} h_{m}(\bar{m}, \bar{a})-\bar{a} h_{a}(\bar{m}, \bar{a})\right], \\
\delta_{2}= & \beta_{2} k_{s}(\bar{s}, \bar{l}, \bar{a}), \\
\delta_{3}= & \beta_{2} k_{l}(\bar{s}, l, \bar{a}), \\
\delta_{4}= & \beta_{3} h_{m}(\bar{m}, \bar{a}), \\
\delta_{5}= & \beta_{2} k_{a}(\bar{s}, l, \bar{a})+\beta_{3} h_{a}(\bar{m}, \bar{a}), \\
\varepsilon_{t}= & \xi_{t}+\text { higher-order terms. }
\end{aligned}
$$

Using a second-order Taylor series expansion for the human capital production function and a first-order Taylor series expansion for the health production function yields the following equation (this is identical to original eq. [5]):

$$
\begin{aligned}
\ln \left(w_{t}\right)= & \beta_{0}+\beta_{1} X_{t}+\beta_{2} K_{0}+\beta_{3} H_{0} \\
& +\gamma_{1}(t-1)+\gamma_{2} \sum_{j=1}^{t-1} s_{j}+\gamma_{3} \sum_{j=1}^{t-1} l_{j}+\gamma_{4} \sum_{j=1}^{t-1} m_{j} \\
& +\gamma_{5} \sum_{j=1}^{t-1} a_{j}+\gamma_{6} \sum_{j=1}^{t-1} s_{j} a_{j}+\gamma_{7} \sum_{j=1}^{t-1} l_{j} a_{j}+\gamma_{8} \sum_{j=1}^{t-1} s_{j} l_{j} \\
& +\gamma_{9} \sum_{j=1}^{t-1} s_{j}^{2}+\gamma_{10} \sum_{j=1}^{t-1} l_{j}^{2}+\gamma_{11} \sum_{j=1}^{t-1} a_{j}^{2}+\varepsilon_{t},
\end{aligned}
$$

where

$$
\begin{aligned}
\gamma_{1} & =\beta_{2} A+\beta_{3}\left[b(\bar{m}, \bar{a})-\bar{m} h_{m}(\bar{m}, \bar{a})-\bar{a} h_{a}(\bar{m}, \bar{a})\right] \\
\gamma_{2} & =\beta_{2} B \\
\gamma_{3} & =\beta_{2} C \\
\gamma_{4} & =\beta_{3} h_{m}(\bar{m}, \bar{a}) \\
\gamma_{5} & =\beta_{2} D+\beta_{3} h_{a}(\bar{m}, \bar{a}), \\
\gamma_{6} & =\beta_{2} k_{s a}(\bar{s}, l, \bar{a}) \\
\gamma_{7} & =\beta_{2} k_{l a}(\bar{s}, \bar{l}, \bar{a}) \\
\gamma_{8} & =\beta_{2} k_{s l}(\bar{s}, l, \bar{a}) \\
\gamma_{9} & =.5 \beta_{2} k_{s s}(\bar{s}, l, \bar{a}) \\
\gamma_{10} & =.5 \beta_{2} k_{l l}(\bar{s}, \bar{l}, \bar{a}), \\
\gamma_{11} & =.5 \beta_{2} k_{a a}(\bar{s}, \bar{l}, \bar{a}),
\end{aligned}
$$




$$
\begin{aligned}
A= & k(\bar{s}, l, \bar{a})-\bar{s} k_{s}(\bar{s}, l, \bar{a})-l k_{l}(\bar{s}, l, \bar{a})-\bar{a} k_{a}(\bar{s}, l, \bar{a}) \\
& +.5 \bar{s} k_{s s}(\bar{s}, l, \bar{a})+.5 l^{2} k_{l l}(\bar{s}, l, \bar{a})+.5 \bar{a} k_{a a}(\bar{s}, l, \bar{a}) 22 \\
& +\bar{s} l k_{s l}(\bar{s}, l, \bar{a})+\bar{s} a k_{s a}(\bar{s}, l, \bar{a})+l \bar{a} k_{a l}(\bar{s}, l, \bar{a}), \\
B= & k_{s}(\bar{s}, \bar{l}, \bar{a})-\bar{l} k_{s l}(\bar{s}, \bar{l}, \bar{a})-\bar{a} k_{s a}(\bar{s}, \bar{l}, \bar{a})-\bar{s} k_{s s}(\bar{s}, \bar{l}, \bar{a}), \\
C= & k_{l}(\bar{s}, l, \bar{a})-l k_{l l}(\bar{s}, l, \bar{a})-\bar{a} k_{l a}(\bar{s}, l, \bar{a})-\bar{s} k_{l s}(\bar{s}, l, \bar{a}), \\
D= & k_{a}(\bar{s}, l, \bar{a})-l k_{a l}(\bar{s}, l, \bar{a})-\bar{a} k_{a a}(\bar{s}, l, \bar{a})-\bar{s} k_{a s}(\bar{s}, l, \bar{a}), \\
\varepsilon_{t}= & \xi_{t}+\text { higher-order terms. }
\end{aligned}
$$

\section{Appendix B}

\section{Derivation of the Likelihood Function}

This appendix derives the likelihood function used in the analysis. To write the full likelihood function, we must first specify all seven equations in the system to be estimated. The empirical wage equation developed in the text is as follows (original eq. [6]):

$$
\begin{aligned}
& \ln \left(w_{i t}\right)=\beta_{w 0}+\beta_{w 1} \operatorname{EDDKN}_{i t}+\beta_{w 2} \mathrm{EDKNW}_{i t}+\beta_{w w} \mathrm{EXPDKN}_{i t} \\
& +\beta_{w 4} \mathrm{EXPDKN}_{i t}+\beta_{w 5} \mathrm{EXPKNW}_{i t}+\beta_{w 6} \mathrm{EXPKNW}_{i t} \\
& +\beta_{w v} \mathrm{DRK}_{i t}+\beta_{w v 8} \mathrm{HVY}_{i t}+\beta_{w \varphi} \mathrm{EDDRK} \\
& +\beta_{w 10} \text { EDHVY }+\beta_{w 11} \text { EXPDRK }+\beta_{w 12} \text { EXPHVY } \\
& +\beta_{w 13} \operatorname{deg}_{i t}+\beta_{\mathrm{w} 14} \boldsymbol{x}_{i t}+u_{w i t} \text {. }
\end{aligned}
$$

Equation (B2) describes the years of education in the initial period:

$$
\text { INITIAL_ED }{ }_{i 1}=\beta_{I 1}+\beta_{I 2} x_{i 1}+\beta_{I 3} z_{i}+\beta_{I 4} p_{i o}+u_{I i 1} \text {. }
$$

As in equation (B1/original eq. [6]) which is identical to original equation (6), the it subscript refers to individual $i$ in period $t$, the $\beta$ s are coefficients to be estimated, $\mathbf{x}_{i 1}$ is the same vector of demographic and labor market characteristics that appeared in equation (B1/original eq. [6]), and $u_{I i 1}$ is an error term whose distribution will be discussed below. Variable INITIAL_ED $D_{i 1}$ is a stock variable reflecting the years of education completed prior to period 1 . The vector $\mathbf{z}_{i}$ is the set of exogenous family background variables described earlier. The vector $\mathbf{p}_{i 0}$ is a subset of state-level policy variables described earlier and measured as of 1978. These policies are measured as of 1978 because we are modeling the years of education completed prior to 1979 , and therefore the relevant policies are those faced by the individual in 1978. Because all respondents were below the MLDA in 1978, the policy variables concerning the MLDA have been 
excluded. Family income is not included because family income is a potentially endogenous variable.

Equation (B3) describes the decision to be enrolled in school in a given period:

$$
\begin{aligned}
& \mathrm{SCHOOL}_{i t} \\
& \quad= \begin{cases}1 & \text { if } s_{i t}=\beta_{S, 0}+\beta_{S, 1} \boldsymbol{x}_{i t}+\beta_{S, 2} \mathrm{p}_{i t}+\beta_{S, 3} \text { STOCKS }_{i t}+u_{S, i t}>0 \\
0 & \text { otherwise. }\end{cases}
\end{aligned}
$$

Variable $\mathrm{SCHOOL}_{i t}$ is an indicator variable that equals one if the individual is enrolled in period $t$ and zero otherwise, and $u_{s i t}$ is an error term whose distribution will be discussed below. The individual will be enrolled if the unobserved hours of schooling demanded, $s_{i t}$, are greater than zero. Vector STOCKS $_{i t}$ represents all of the education, experience, and alcohol use stock variables that appear in equation (B1/original eq. [6]). All other terms are as defined previously.

Equation (B4) describes alcohol use, and equation (B5) describes heavy alcohol use:

\section{$\operatorname{ALCMON}_{i t}$}

$$
= \begin{cases}1 & \text { if } a_{i t}=\beta_{A, 0}+\beta_{A, 1} x_{i t}+\beta_{A, 2} p_{i t}+\beta_{\mathrm{A}, 3} \text { STOCKS }_{\mathrm{it}}+u_{A, i t}>0 \\ 0 & \text { otherwise. }\end{cases}
$$

$$
\begin{aligned}
& \text { HVYDRK }\left._{i t}\right|_{\mathrm{ALCMON}_{i t=1}} \\
& \quad= \begin{cases}1 & \text { if } a_{i t}=\beta_{H D, 0}+\beta_{H D, 1} x_{i t}+\beta_{H D, 2} p_{i t}+\beta_{H D, 3}+u_{H D, i t}>\alpha \\
0 & \text { otherwise. }\end{cases}
\end{aligned}
$$

Variables ALCMON $i t$ and HVYDRK $_{i t}$ are indicators reflecting alcohol use and heavy use, respectively; $a_{i t}$ is the number of alcoholic drinks demanded by the individual in period $t$; and $\alpha$ is the level of alcohol use above which use is considered to be heavy (i.e., six or more drinks on three or more occasions in the past month). All other variables are as defined previously.

Equations (B6) and (B7) describe the labor supply process:

$$
\text { EMPLD }\left._{i t}\right|_{\mathrm{SCHOOL}_{i t}=0}
$$

$$
=\left\{\begin{array}{ll}
1 & 1 \text { if HOURS } \\
0 & \text { otherwise. }
\end{array}=\beta_{E, 0}+\beta_{E, 1} x_{i t}+\beta_{E, 2} p_{i t}+\beta_{E, 3} \text { STOCKS }_{i t}+u_{E, i t}>0\right.
$$




$$
\begin{aligned}
\text { HOURS }\left._{i t}\right|_{\mathrm{EMPLD}_{i t}=1}= & \beta_{H W, 0}+\beta_{H W, 1} \boldsymbol{x}_{i t}+\beta_{H W, 2} p_{i t} \\
& +\beta_{H W, 3} \text { STOCKS }_{i t}+u_{H W, i t} .
\end{aligned}
$$

Variable EMPLD $\mathrm{EL}_{i t}$ equals one if individual $i$ works in period $t$ and is zero otherwise, and variable $\mathrm{HOURS}_{i t}$ is the actual number of hours worked by individual $i$ conditional on individual $i$ working. As discussed earlier, we only consider the wages of those individuals who are not enrolled in school. Because of this, an individual's hours of work are modeled only if he or she is not enrolled in school and had an observed wage.

Equation (B8) describes the error structure of the model:

$$
\begin{aligned}
& u_{I i 1}=\eta_{I i}+\varepsilon_{I i} \\
& u_{j i t}=\eta_{j i}+\nu_{j i t}+\varepsilon_{j i t} ; j=W, S, A, H D, E, H W .
\end{aligned}
$$

Equation (B8) decomposes the error terms in the system of equations into three components. The $\eta$ 's are time-constant person-specific factors that follow a seven-dimensioned multivariate distribution (there are seven equations in the system). The $\nu$ 's are time-varying person-specific factors that follow a six-dimensioned multivariate distribution (there are six timevarying equations in the system). Because equation (B2), the initial years of education, is estimated only for 1979, a single, time constant error component captures all unobserved heterogeneity in that equation. The $\varepsilon$ 's are normally distributed independent error terms with mean zero and standard deviation $\sigma_{j}$ for continuous outcomes and logistically distributed for discrete outcomes.

Before presenting the full likelihood function, it will be useful to define some more compact notation. Let $\mathbf{X}_{j i t} \mathbf{B}_{j}$ denote the observable right-handside variables and coefficients of equation $j$. Using this notation, equations (B1)-(B7) can be rewritten as follows:

$$
\begin{gathered}
\ln \left(w_{i t}\right)=\boldsymbol{X}_{W i t} \boldsymbol{B}_{W}+u_{W i t}, \\
\text { INITIAL_ED } \mathrm{ED}_{i 1}=\boldsymbol{X}_{I i t} \boldsymbol{B}_{I}+u_{I i 1}, \\
\text { SCHOOL }_{i t}= \begin{cases}1 & \text { if } s_{i t}=\boldsymbol{X}_{S i t} \boldsymbol{B}_{S}+u_{S i t}>0, \\
0 & \text { otherwise. }\end{cases} \\
\text { ALCMON }_{i t}= \begin{cases}1 & \text { if } a_{i t}=\boldsymbol{X}_{A i t} \boldsymbol{B}_{A}+u_{A i t}>0, \\
0 & \text { otherwise. }\end{cases} \\
\text { HVYDRK }\left._{i t}\right|_{\mathrm{ALCMON}_{i t}=1}= \begin{cases}0 & 1 \text { if } \boldsymbol{a}_{i t}=\boldsymbol{X}_{H D i t} \boldsymbol{B}_{H D}+u_{H D i t}>\alpha, \\
1 & \text { otherwise. }\end{cases} \\
\text { EMPLD }\left._{i t}\right|_{\text {SCHOOL }_{i t}=0}=\left\{\begin{array}{ll}
1 & \text { if HOURS } \\
0 & \text { otherwise. }
\end{array}=\mathbf{X}_{E i t} \mathbf{B}_{E}+u_{E i t}>0,\right.
\end{gathered}
$$




$$
\left.\mathrm{HOURS}_{i t}\right|_{\mathrm{EMPLD}_{i t}=1}=\boldsymbol{X}_{H W i t} \boldsymbol{B}_{H W}+u_{H W i t} \text {. }
$$

Using this new notation and equation (B8), the likelihood function for the empirical model is

$$
\begin{aligned}
& \mathrm{L}=\prod_{i=1}^{N} \sum_{j=1}^{J} \pi_{\eta j} \prod_{t=1}^{T} \sum_{k=1}^{K} \pi_{\nu k}\left[\frac{1}{\sigma_{W}} \phi\left(\frac{\ln \left(w_{i t}\right)-\boldsymbol{X}_{W i t} \boldsymbol{B}_{W}-\eta_{W j}-\nu_{W k}}{\sigma_{W}}\right)\right]^{\mathrm{EMPLD}_{i t} \times\left(1-\mathrm{SCHOOL}_{i t}\right.}
\end{aligned}
$$

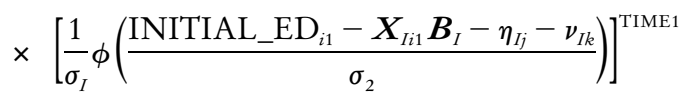

$$
\begin{aligned}
& \times\left[\frac{1}{\sigma_{H W}} \phi\left(\frac{\mathrm{HOURS}_{i t}-\boldsymbol{X}_{H W i t} \boldsymbol{B}_{H W}-\eta_{H W j}-\nu_{H W k}}{\sigma_{8}}\right)\right]^{\mathrm{EMPLD}_{i t} \times\left(1-\mathrm{SCHOOL}_{i t}\right)}
\end{aligned}
$$

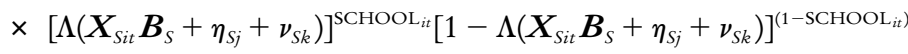

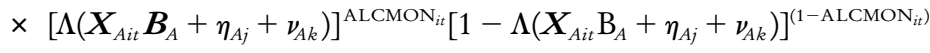

$$
\begin{aligned}
& \times\left[\Lambda\left(\boldsymbol{X}_{H D i t} \boldsymbol{B}_{H D}+\eta_{H D j}+\nu_{H D k}\right)\right]^{\mathrm{HVYDRK}_{i t}} \\
& \times\left[1-\Lambda\left(\boldsymbol{X}_{H D i t} \boldsymbol{B}_{H D}+\eta_{H D j}+\nu_{H D k}\right)\right]^{\left(1-\mathrm{HVYDRK}_{i t}\right)} \\
& \times\left[\Lambda\left(\boldsymbol{X}_{E i t} \boldsymbol{B}_{E}+\eta_{E j}+\nu_{E k}\right)\right]^{\mathrm{EMPLD}_{i t} \times\left(1-\mathrm{SCHOOL}_{i t}\right)} \\
& \times\left[1-\Lambda\left(\boldsymbol{X}_{E i t} \boldsymbol{B}_{E}+\eta_{E j}+\nu_{E k}\right)\right]^{\left(1-\mathrm{EMPLD}_{i t}\right) \times\left(1-\mathrm{SCHOOL}_{i t}\right)},
\end{aligned}
$$

where TIME1 is an indicator variable that equals one if $t=1$ and zero otherwise, $\phi(\cdot)$ is the standard normal probability distribution function, and $\Lambda(\cdot)$ is the logistic cumulative distribution function. All other variables are as defined previously.

\section{References}

$\rightarrow$ Ashenfelter, Orley, and David Zimmerman. 1997. Estimates of the return to schooling from sibling data: Fathers, sons, and brothers. Review of Economics and Statistics 79, no. 1:1-9.

Baum, Christopher F., Mark E. Schaffer, and Steven Stillman. 2003. Instrumental variables and GMM: Estimation and testing. Working paper no. 545, Department of Economics, Boston College.

$\rightarrow$ Berger, Mark C., and J. Paul Leigh. 1988. The effect of alcohol use on wages. Applied Economics 20 (October): 1343-51.

Bray, Jeremy W. 2000. Identifying inputs to the human capital production function: The effects of alcohol use on human capital formation. $\mathrm{PhD}$ diss., Department of Economics, University of North Carolina at Chapel Hill.

$\rightarrow$ Bray, Jeremy W., Gary A. Zarkin, Chris Ringwalt, and Junfeng Qi. 2000. The relationship between marijuana initiation and dropping out of high school. Health Economics 9, no. 1:9-18.

$\rightarrow$ Bryant, Richard R., V. A. Sumaranayake, and Allen Wilhite. 1992. Alcohol use and wages of young men: Whites vs. nonwhites. International Review of Applied Economics 6, no. 2:184-202. 
$\rightarrow$ - 2000. The effect of drug use on wages: A human capital interpretation. American Journal of Drug Alcobol Abuse 26, no. 4:659-82.

Card, David. 1999. The causal effect of education on earnings. In Handbook of labor economics, vol. 3, ed. Orley C. Ashenfelter and David Card, 1801-63. Amsterdam: Elsevier.

Carey, Kate B., and Stephen A. Maisto. 1987. Effect of a change in drinking pattern on the cognitive function of female social drinkers. Journal of Studies on Alcobol 48, no. 3:236-42.

Center for Human Resource Research. 1995. NLS users' guide. Columbus: Center for Human Resource Research, Ohio State University.

Conneely, Karen, and Roope Uusitalo. 1997. Estimating heterogeneous treatment effects in the Becker schooling model. Unpublished discussion paper, Industrial Relations Section, Princeton University.

$\rightarrow$ Cook, Phillip J., and Michael J. Moore. 1993. Drinking and schooling. Journal of Health Economics 12, no. 4:411-29.

. 2000. Alcohol. In Handbook of health economics, vol. 1b, ed. Anthony Culyer and Joseph Newhouse, 629-74. Amsterdam: Elsevier.

$\rightarrow$ Dee, Thomas S., and William N. Evans. 2003. Teen drinking and educational attainment: Evidence from two-sample instrumental variables estimates. Journal of Labor Economics 21, no. 1:178-209.

$\rightarrow$ Doll, Richard. 1998. The benefit of alcohol in moderation. Drug and Alcobol Review 17, no. 4:353-63.

Dufour, Mary C., and M. Fe Caces. 1993. Epidemiology of the medical consequences of alcohol. Alcohol Health and Research World 17, no. 3:265-71.

$\rightarrow$ Elias, Penelope K., Merrill F. Elias, Ralph B. D’Agostino, Halit Silbershatz, and Phillip A. Wolf. 1999. Alcohol consumption and cognitive performance in the Framingham heart study. American Journal of Epidemiology 150, no. 6:580-89.

$\rightarrow$ French, Michael T., and Gary T. Zarkin. 1995. Is moderate alcohol use related to wages? Evidence from four worksites. Journal of Health Economics 14, no. 3:319-44.

GAO (General Accounting Office). 1991. Teenage drug use: Uncertain linkages with either pregnancy or school dropout. GAO/PEMD-91-3. Report to the Chairman, Select Committee on Narcotics Abuse and Control, House of Representatives, Washington, DC.

Hannon, Roseann, Charles Butler, Carol Lynn Day, Steven A. Khan, Lupo A. Quitoriano, Annette M. Butler, and Lawrence A. Meredith. 1985. Alcohol use and cognitive functioning in men and women college students. In Recent developments in alcoholism, vol. 1, ed. M. Galanter. New York: Plenum.

$\rightarrow$ Heckman, James, and Burton Singer. 1984. A method for minimizing the impact of distributional assumptions in econometric models for duration data. Econometrica 52, no. 2:271-320.

$\rightarrow$ Heien, Dale M. 1996. Do drinkers earn less? Southern Economic Journal 63, no. 1:60-68.

Kenkel, Donald S., and David C. Ribar. 1994. Alcohol consumption and 
young adults' socioeconomic status. Brookings Papers on Economic Activity: Microeconomics, no. 1:119-61.

Kenkel, Donald, and P. Wang. 1999. Are alcoholics in bad jobs? In The economic analysis of substance use and abuse, ed. Frank Chaloupka, Michael Grossman, Warren Bickel, and Henry Saffer, 251-78. Chicago: University of Chicago Press.

Killingsworth, Mark R., and James J. Heckman. 1992. Female labor supply: A survey. In Handbook of labor economics, vol. 1, ed. Orley C. Ashenfelter and Richard Layard, 103-204. Amsterdam: Elsevier.

$\rightarrow$ Koch, Steven F., and David C. Ribar. 2001. A siblings analysis of the effects of alcohol consumption onset on educational attainment. Contemporary Economic Policy 19, no. 2:162-74.

$\rightarrow$ MaCurdy, Thomas, Thomas A. Mroz, and Mark R. Gritz. 1998. An evaluation of the National Longitudinal Survey on Youth. Journal of Human Resources 33, no. 2:345-436.

$\rightarrow$ Mroz, Thomas A. 1987. The sensitivity of an empirical model of married women's hours of work to economic and statistical assumptions. Econometrica 55, no. 4:765-99.

$\rightarrow \longrightarrow$. 1999. Discrete factor approximations in simultaneous equation models: Estimating the impact of a dummy endogenous variable on a continuous outcome. Journal of Econometrics 92, no. 2:233-74.

Mroz, Thomas A., and Brian J. Surette. 1998. Post-secondary schooling and training effects on wages and employment. Working paper, Department of Economics, University of North Carolina at Chapel Hill.

$\rightarrow$ Mullahy, John, and Jody L. Sindelar. 1989. Life-cycle effects of alcoholism on education, earnings, and occupation. Inquiry 26, no. 2:272-82.

- 1992. Effects of alcohol on labor market success: Income, earnings, labor supply, and occupation. Alcohol Health and Research World 16, no. 2:134-39.

$\rightarrow \longrightarrow$. 1993. Alcoholism, work, and income. Journal of Labor Economics 11, no. 3:494-520.

$\rightarrow-$ 1996. Employment, unemployment, and problem drinking. Journal of Health Economics 15, no. 4:409-34.

$\rightarrow$ Parker, Douglas, A., Elizabeth S. Parker, Jacob A. Brody, and Ronald Schoenberg. 1983. Alcohol use and cognitive loss among employed men and women. American Journal of Public Health 73, no. 5:521-26.

Parker, Elizabeth S., and Ernest P. Nobel. 1977. Alcohol consumption and cognitive functioning in social drinkers. Journal of Studies on Alcohol 38, no. 7:1224-32.

SAMHSA (Substance Abuse and Mental Health Services Administration). 2002. Highlights: National Household Survey on Drug Abuse. Available at http://www.samhsa.gov/oas/NHSDA/2kNHSDA/highlights.htm, last updated on February 14, 2002.

Savage, Timothy H. 1999. The long-term effects of youth unemployment. PhD diss., Department of Economics, University of North Carolina, Chapel Hill.

$\rightarrow$ Staiger, Douglas, and James H. Stock. 1997. Instrumental variables regression with weak instruments. Econometrica 65, no. 3:557-86. 
Stock, James H., and Motohiro Yogo. 2004. Testing for weak instruments in linear IV regression. Discussion Paper no. TO284, National Bureau of Economic Research, Cambridge, MA.

Willis, Robert J. 1992. Wage determinants: A survey and reinterpretation of human capital earnings functions. In Handbook of labor economics, vol. 1, ed. Orley Ashenfelter and Richard Layard. New York: North Holland.

$\rightarrow$ Wolaver, Amy M. 2002. Effects of heavy drinking in college on study effort, grade point average, and major choice. Contemporary Economic Policy 20, no. 4:415-28.

$\rightarrow$ Yamada, Tetsuji, Michael Kendix, and Tadashi Yamada. 1996. The impact of alcohol consumption and marijuana use on high school graduation. Health Economics 5, no. 1:77-92.

$\rightarrow$ Zarkin, Gary A., Michael T. French, Thomas A. Mroz, and Jeremy W. Bray. 1998. Alcohol use and wages: New results from the National Household Survey on Drug Abuse. Journal of Health Economics 17, no. 1:53-68. 